\title{
Reseña
}

Review

\section{Zambrano Cardona, Camilo Alexander. Luisa de Venero, una encomendera de Santafé. Microhistoria de las mujeres encomenderas en el Nuevo Reino de Granada, siglo XVI. Bogotá: Universidad del Rosario, 2019, 191 pp.}

\author{
Laura Daniela Perdomo Ramos \\ Universidad Autónoma de Colombia, Colombia \\ daniela.perdomo29@hotmail.com
}

Fecha de recepción: 16 de agosto de 2020 Fecha de aceptación: 13 de octubre de 2020

En el texto Luisa de Venero, una encomendera de Santafé. Microhistoria de las mujeres encomenderas en el Nuevo Reino de Granada, siglo XVI, el historiador Camilo Zambrano se centra en dar a conocer y entender la participación de las mujeres en la Colonia debido a que esta ha sido vista convencionalmente desde una perspectiva androcéntrica - como él mismo lo menciona-, condenando lo femenino a la invisibilidad. En el texto se expone la vida de una mujer encomendera en la sociedad colonial de la Nueva Granada, doña Luisa de Venero. El objetivo del escrito es mostrar a la mujer colonial en un rol activo en la sociedad partiendo de las mujeres encomenderas.

El texto tiene un enfoque microhistórico de la vida de la encomendera Luisa de Venero. A través del análisis de su vida, y en especial de un conflicto judicial que afrontó sobre su encomienda, se reconstruye el papel de la mujer en otros aspectos de la vida colonial que suelen dejarse de lado: "Las investigaciones históricas colombianas sobre las mujeres coloniales se dirigían a cuestiones acerca del género y la etnicidad, dejando por fuera la interacción de aquellas con las instituciones económicas, políticas y sociales"1.

El libro está dividido en tres capítulos. En el primero, Zambrano expone un estudio general de la ciudad de Santafé desde su fundación en 1538 y su posterior organización, para mencionar en dónde estaba ubicada la casa de la encomendera Luisa

1 Camilo Zambrano, Luisa de Venero, una encomendera de Santafé. Microhistoria de las mujeres encomenderas en el Nuevo Reino de Granada, siglo XVI (Bogotá: Universidad del Rosario, 2019), 151. 
de Venero $^{2}$, pues esta propiedad no era la única que poseía. Se presentan, además, las condiciones climáticas que había en la tierra de esta encomendera y, posteriormente, se dedica un apartado sobre el contexto político y económico, mencionando a la Real Audiencia y la Real Hacienda junto con su organización y funcionamiento, información que permite obtener una contextualización que, aunque se torna extensa, busca explicar por qué, según Zambrano, la mujer no tuvo cabida en el mundo de las instituciones coloniales.

En el siguiente apartado se habla acerca de las relaciones económicas de este periodo y de cómo se generaba el sustento y el abastecimiento de los habitantes y de las ciudades. En este mismo capítulo Zambrano muestra las improntas del sistema colonial a través de los personajes más destacados, por ejemplo, los colonos, los colonizados, los religiosos y las mujeres de la sociedad colonial, para el caso de la encomienda. Por medio de estos personajes, que cumplían un papel importante en la sociedad, Zambrano muestra cómo esta cultura dio un mayor mérito a los hombres que a las mujeres, situación que era ampliamente aceptada en aquella época. Recordemos que la sociedad colonial fue casi en su totalidad religiosa y su fe oficial era el catolicismo, lo que hizo común y aceptable un rol masculino predominante y un rol femenino sumiso.

Durante el desarrollo del mismo capítulo primero, donde se explican las generalidades de la época, se podría pensar que las problemáticas que tuvo la encomienda se abordarían más profundamente; sin embargo, se menciona escasamente, por ejemplo, la crisis demográfica que causó esta institución en la población nativa.

Volviendo al tema que le interesa al autor, es decir, el de las mujeres en la sociedad colonial y cómo según investigaciones históricas tuvieron una importante acción en la colonización y construcción del centro urbano, se destaca que también criticaron al sistema patriarcal, arraigado en el catolicismo y que fue transmitido por la Iglesia3. Respecto a esta "crítica", Zambrano explica cómo el sistema colonial se vio debilitado al punto que permitió que una mujer llegase a ocupar un cargo que era exclusivamente masculino (encomenderos), y desde esa posición de privilegio de las mujeres encomenderas se cuestionó el sistema patriarcal colonial en el que vivieron. Sin embargo, también se encuentra una tesis contraria a lo que plantea Zambrano, y es la de Perdomo, en donde plantea que "el surgimiento de estas encomenderas en Tierra Firme permitió que se fortalecieran las elites locales, autoridades metropolitanas y la corona, por el desarrollo del linaje, que esto implica"4. Para Perdomo, lo que permitió

2 La casa que ocupaba esta encomendera parece ser otorgada por el cabildo, esto demuestra su posición de nobleza, debido a que estos predios solo eran otorgados a las familias de los conquistadores.

3 Zambrano se refiere a esta como "la corporación eclesiástica". Ibid., 40.

4 Óscar Perdomo, Las señoras de los indios: el papel de la división social del trabajo a partir del parentesco en el desarrollo de la encomienda en la Tierra Firme, 1510-1630 (Bogotá: Instituto Colombiano de Antropología e Historia, 2016), 41. 
el surgimiento de las encomenderas fue el fortalecimiento de las autoridades y de la élites que pudieron, por medio de la figura de la mujer encomendera, conservar las encomiendas en sus familias por varias vidas.

El autor utiliza también el concepto de patriarcalismo como una "categoría sociológica" ${ }^{5}$ que opera en el contexto del libro para establecer que las relaciones sociales, económicas y políticas no fueron dirigidas del todo por el patriarca, sino que existió una difusa participación femenina. Con el patriarcalismo se le atribuye a la mujer colonial una individualidad que le permite influir no solo en su vida, sino también en aspectos de la vida colonial, lo que se supone no debería poder hacer. Referente a la idea de individualidad que suele asumirse para este periodo, Óscar Perdomo señala que en la historia las relaciones de género deben ser entendidas a través de la prevalencia del individuo sobre la comunidad. Sin embargo, en la sociedad colonial sucedía todo lo contrario, así que no es posible entender el rol del individuo como un agente identificable en el círculo social debido a que en este periodo el concepto de individuo no existía; era, entonces, representado por sus grupos familiares, es decir, eran estos los que permitían la formación de una identidad y solo a través de ellos podía una mujer convertirse en encomendera.

Por lo general estas mujeres no buscaban llegar al cargo de encomenderas. Al contrario: "la mayoría de las mujeres encomenderas accedió a este título por medio de la herencia ya sea por parte de su padre o esposo". Aunque Zambrano tenga claro esto, parece interpretarlo de forma diferente.

En otra definición de patriarcalismo que da el autor a lo largo del texto menciona:

En el sentido de la crítica moderna, opera en este contexto únicamente para establecer las relaciones sociales de opresión sobre las mujeres españolas que hay dentro de las expediciones de conquista, como paso previo al establecimiento de una sociedad colonial, y por ello, de mujeres encomenderas ${ }^{7}$.

Siguiendo esta idea Zambrano habla acerca de cómo las relaciones de opresión permean la encomienda y se ven envueltas en el patriarcalismo. Esto permite asumir que todas las instituciones de la época están influenciadas por el patriarcalismo, fenómeno natural en el tipo de sociedad que estamos estudiando. Continuando con esta idea, podríamos establecer que implantar una categoría moderna a una institución de hace cinco siglos parece ser anacrónico y causa ciertas dificultades a la hora de abordar la encomienda y las encomenderas.

$5 \quad$ Zambrano, Luisa de Venero, 41.

$6 \quad$ Perdomo, Las señoras de los indios, 41.

7 Zambrano, Luisa de Venero, 41. 
En este mismo apartado se explica la forma en que se permitió que las mujeres pudieran acceder a la encomienda, esto debido a que desde 1536 la Corona autorizó concederla a través del linaje. Solo la esposa o la hija del encomendero podrían poseer la encomienda, lo que nos muestra que las disposiciones reales mismas permitieron que hubiera encomenderas. Por ende, la existencia de ellas no significa un debilitamiento de las instituciones, aunque posteriormente se busque su regulación; la existencia de este cargo para mujeres fue completamente válido. Recordemos que dichas mujeres podían acceder a esta posición porque venían de familias pudientes de ascendencia española que buscaban mantener en su poder las encomiendas por más de una vida sin importar que la única forma de lograrlo fuera tener una mujer a cargo de ella, lo que les permitió tener un papel destacado en la sociedad en comparación con el resto de las mujeres de la época.

Zambrano relata la vida detallada de doña Luisa de Venero, una mujer que heredó su encomienda por su segundo marido y tuvo ciertos inconvenientes con capitanes indígenas de la zona. Para conocer el conflicto a profundidad, el autor realiza un contexto histórico, político y jurídico del pleito de doña Luisa, y es aquí donde aclara que hace una investigación ligada a la microhistoria, en la que se muestra la participación jurídica de esta encomendera. Esto permite entender su papel activo en el contexto regional de la época debido a que la encomendera Luisa de Venero se ve envuelta en un pleito en el que, para Zambrano, "una de las capacidades más notorias desarrolladas por Luisa de Venero en el pleito fue el manejo, la apropiación y aplicación de los mecanismos litigiosos". De esta capacidad que menciona el autor se construye esta idea de la encomendera como un personaje que encara un sistema judicial patriarcal desde su rol inferior. No obstante, recordemos que doña Luisa no era cualquier mujer, ella provenía de una familia acomodada que tenía amistades en cargos importantes, entre ellos "el doctor Venero de Leiva, presidente y gobernador del reino que le concedió a doña Luisa una estancia de ganado mayor en tierra y términos de Simijaca". El poder al que podía acceder esta mujer fue suficiente para enfrentar el pleito sin mayor problema. Asimismo, la mayoría de las encomenderas hicieron parte de la élite colonial, lo que les permitió mantener su posición y tener un mejor trato por parte de las autoridades. Durante el resto del capítulo se habla del testamento de doña Luisa de Venero, en donde se especifican todas las indicaciones para su entierro y quién notificó su muerte.

En el tercer capítulo, titulado "Las encomenderas en la visión de los contemporáneos y en la imagen colombiana del siglo XIX", se trata la representación de diferentes autores sobre una encomendera de mediados el siglo XVI. En el primer texto que se aborda — La sucesión de mujeres en la encomienda según la política indiana de don Juan de Solórzano y Pereira-, Juan de Solórzano manifiesta que no considera

$\begin{array}{ll}8 & \text { Ibid., } 59 . \\ 9 & \text { Ibid., } 63 .\end{array}$


conveniente que la mujer esté a cargo de encomiendas basándose en leyes anteriores y en creencias religiosas que señalan los roles de las mujeres. El tema es tratado desde las leyes que tratan la sucesión, medio por el cual las mujeres podían llegar a poseer una encomienda. Este apartado se centra en el análisis de leyes que expone Juan de Solórzano.

Respecto al segundo escrito, El carnero, de Juan Rodríguez Freyle, se hace referencia a una encomendera que se vio envuelta en una disputa por los "robos" que cometió un indígena que huyó hasta la casa de dicha encomendera debido a que allí se encontraba un cura doctrinero al cual servía el indígena. En el libro el autor da a conocer el pleito de forma detallada, sin embargo, el texto de Freyle se enfoca más en la oficialidad real. Por otro lado, se señala que al final del pleito la encomendera debió responder con una restitución monetaria y el pago de costas del proceso. En este capítulo Zambrano habla de una postura misógina por parte de Freyle, lo cual es problemático porque se está atribuyendo a un escritor colonial un concepto moderno que se refiere a la aversión a las mujeres. Probablemente Freyle no sufría de esto; más bien sus ideas son producto de pertenecer a una sociedad colonial en donde la mujer no es vista como igual al hombre. No es algo reprochable o "machista" como lo veríamos hoy, porque son sociedades completamente diferentes y no podemos trasladar concepciones modernas para valorar el pasado. Es importante resaltar que la obra de Freyle es literaria.

En el relato de José Caicedo y Rojas, titulado La bella encomendera, se narra de forma detallada el asesinato de una encomendera. Zambrano toma este relato para poder comprender la manera en la que era vista la mujer junto con la mujer encomendera en el siglo XIX. Respecto a este apartado no se hace mayor análisis y se concluye que es un texto que lleva a conclusiones semejantes a las del texto Freyle.

Zambrano concluye su libro resaltando la participación de las mujeres encomenderas en un escenario jurídico, económico y cultural, un aspecto que para el autor ha sido poco visibilizado en las investigaciones históricas colombianas coloniales, y que esta investigación aporta a otras en las que se estudie sobre las relaciones de poder, la historia social de las mujeres, la historia cultural y estudios de género. Referente a esto, las investigaciones acerca de encomenderas en el país son muy escasas y se han escrito solo dos libros sobre el tema y un artículo. En Latinoamérica se ha abordado este tema en Perú principalmente, pero de igual forma, son pocas las investigaciones al respecto.

\section{Referencias}

Perdomo, Oscar. Las señoras de los indios: el papel de la división social del trabajo a partir del parentesco en el desarrollo de la encomienda en la Tierra Firme, 1510-1630. Bogotá: Instituto Colombiano de Antropología e Historia, 2016. 
Zambrano, Camilo. Luisa de Venero, una encomendera de Santafé. Microhistoria de las mujeres encomenderas en el Nuevo Reino de Granada, siglo XVI. Bogotá: Universidad del Rosario, 2019. 